\title{
Ethanol extract of Psoralea corylifolia L. and its main constituent, bakuchiol, reduce bone loss in ovariectomised Sprague-Dawley rats
}

\author{
Sun-Hye Lim ${ }^{1}$, Tae-Youl Ha ${ }^{1}$, Sung-Ran Kim ${ }^{1}$, Jiyun Ahn ${ }^{1}$, Hyun Jin Park ${ }^{2}$ and Suna Kim ${ }^{1}$. \\ ${ }^{1}$ Food Function Research Group, Korea Food Research Institute, Gyeonggi-Do 463-746, South Korea \\ ${ }^{2}$ Graduate School of Biotechnology, Korea University, Seoul 136-701, South Korea \\ (Received 7 November 2007 - Revised 8 July 2008 - Accepted 14 July 2008 - First published online 19 September 2008)
}

The aim of the present study was to investigate whether ethanol extracts of Psoralea corylifolia L. (PCE) and its active component protect against bone loss in ovariectomised rats. We screened oestrogenic activities of the main extract fractions using in vitro assays and identified bakuchiol as the most active oestrogenic component by HPLC and LC/MS, and then demonstrated that bakuchiol had strong binding affinity for oestrogen receptor (ER) $\alpha$. Seventy female Sprague-Dawley rats were assigned to either a sham-operated group $(n 10)$ or an ovariectomised group $(n 60)$. The ovariectomised group was subdivided into six groups, each containing ten rats: vehicle group, two bakuchiol-treated groups (dose of $15 \mathrm{mg} / \mathrm{kg}$ per $\mathrm{d}$ or $30 \mathrm{mg} / \mathrm{kg}$ per $\mathrm{d}$; ten rats for each group), two PCE-supplemented groups $(0.25 \%$ or $0.5 \%$ extracts of diets; ten rats for each group) and a $17 \beta$-oestradiol (E2)-treated group $(20 \mu \mathrm{g} / \mathrm{kg}$ per d). We recorded weight and feed intake every week, and killed all animals after 6 weeks. Blood was collected, and the uterus, kidneys and livers were removed. Bakuchiol has a three-fold higher binding affinity for ER $\alpha$ than for ER $\beta$. Bakuchiol and PCE treatments had no uterotrophic activity even though they demonstrated oestrogenic activity in the in vitro assays. Bakuchiol and PCE treatments reduced postmenopausal bone loss by increasing alkaline phosphatase, Ca concentrations, serum E2 concentration and bone mineral density, and by decreasing the inorganic P level. The present study indicated that bakuchiol and PCE treatments could protect against bone loss.

Psoralea corylifolia: Bakuchiol: Ovariectomy: Bone loss

Menopausal women have a higher risk of uterine fibroids, fibrocystic breast disease, breast or uterine cancer, CHD and obesity $^{(1,2)}$. The most prevalent disease in postmenopausal women is osteoporosis, a disorder of excess skeletal fragility caused partly by changes in bone microstructure ${ }^{(3,4)}$. Hormone-replacement therapy (HRT) is currently used to treat osteoporosis or to reduce the symptoms of the menopause, even though HRT has a risk of adverse side effects including breast cancer and endometrial adenocarcinoma ${ }^{(5)}$.

Concerns about the adverse side effects of HRT have led to interest in phyto-oestrogens, which are natural alternatives to HRT. Treatment with phyto-oestrogens such as equol, genistein and daidzein has shown favourable effects on bone metabolism, lipid metabolism, obesity and inhibition of menopausal symptoms ${ }^{(6-8)}$. However, they are also associated with uterotrophic effects, which may increase the risk of endometrial cancer ${ }^{(7,9)}$. Therefore, the development of new phyto-oestrogens with minimal uterotrophic effects is an urgent research focus.

Psoralea corylifolia L. is a widely used medicinal plant in Asia and India ${ }^{(5,10)}$. The seeds of $P$. corylifolia $L$. exert antioxidative, antimicrobial and anti-inflammatory activities $^{(11-13)}$. Recent research suggests that $P$. corylifolia has potent oestrogenic effects and that its seeds may be a useful remedy for bone fractures, osteomalacia and osteoporosis $^{(10,14)}$. Components derived from $P$. corylifolia, including bakuchiol, corylifolia, corylin, psoralidin and isobavachin, have strong antioxidant activities ${ }^{(11)}$, and corylin and bavachin have been shown to stimulate osteoblastic proliferation ${ }^{(15)}$. However, little information is available concerning the oestrogenic characteristics of $P$. corylifolia $\mathrm{L}$. in animal models.

In the present study, we screened the most oestrogenic component derived from $P$. corylifolia $\mathrm{L}$. by two different in vitro assays, and identified the active component by instrumental analyses such as HPLC and LC/MS, and then compared binding affinities of the component for oestrogen receptor (ER) $\alpha$ and ER $\beta$. We also evaluated the effects of $P$. corylifolia extracts and its active component on body-weight gain, uterine weight and bone loss in ovariectomised rats.

\section{Experimental methods}

\section{Materials and sample preparation}

$P$. corylifolia L. seeds were purchased from a commercial supplier of herbs and pharmaceuticals (Seongnam, Republic of Korea) and were identified by Professor Y. M. Park,

Abbreviations: ALP, alkaline phosphatase; BH, bakuchiol at a high dose of $30 \mathrm{mg} / \mathrm{kg}$ per d; BL, bakuchiol at a low dose of $15 \mathrm{mg} / \mathrm{kg}$ per d; BMD, bone mineral density; E2, 17 $\beta$-oestradiol; ER, oestrogen receptor; HRT, hormone-replacement therapy; $\mathrm{IC}_{50}$, half maximal inhibitory concentration; IP, inorganic-phosphorus; PCE, ethanol extract of Psoralea corylifolia L.; OE, $17 \beta$-oestradiol at $20 \mu \mathrm{g} / \mathrm{kg}$ per d; OVX, ovariectomised vehicle-treated control; PH, Psoralea corylifolia L. extract at a high dose of $0.5 \%$; PL, Psoralea corylifolia L. extract at a low dose of $0.25 \%$; RBA, relative binding affinity; Sham, sham-operated.

* Corresponding author: Dr Suna Kim, fax +82 31780 9225, email suna@kfri.re.kr 
Department of Life Science, Cheongju University (Cheonju, Republic of Korea). Voucher specimens (KFRI-PM03220) were preserved in the Korea Food Research Institute. Psoralen and bavachinin were purchased from Sigma Co. (St Louis, MO, USA), and bakuchiol, bavachalcone, isobavachalcone, bavachromene and isobavachromene isolated from $P$. corylifolia L. were obtained from the Korea Research Institute of Chemical Technology (Daejeon, Republic of Korea) as standard compounds for instrumental analyses (purities $>98 \%$ by HPLC, LC/MS, IR and ${ }^{1} \mathrm{H}$ and ${ }^{13} \mathrm{C}$ NMR spectroscopy). Catechin and 17 $\beta$-oestradiol (E2) were purchased from Sigma Co. All other chemicals were of analytical grade (Fisher, Springfield, NJ, USA).

Dried seeds $(300 \mathrm{~g})$ were washed and boiled in 3 litres of $80 \%$ ethanol at $95^{\circ} \mathrm{C}$ for $4 \mathrm{~h}$, and the ethanol extract of $P$. corylifolia L. (PCE) was filtered through no. 2 filter paper (Whatman International Ltd, Maidstone, Kent, UK). A portion of PCE $(1 \mathrm{ml})$ was used for fractionation, and the remainder was dried using a rotary evaporator (Rotavapor R-200; Buchi, Postfach, Switzerland) and stored at $4^{\circ} \mathrm{C}$ until it was used to prepare the diets.

\section{Screening of oestrogenicity and identification of active component}

A quantity of $1 \mathrm{ml}$ of PCE $\left(25^{\circ} \mathrm{Bx}\right)$ was diluted to $15^{\circ} \mathrm{Bx}$ using $80 \%$ ethanol, and ninety fractions (each $5 \mathrm{ml}$ ) were obtained by gel chromatography $(1.5 \times 120 \mathrm{~cm}, 1 \mathrm{ml} / \mathrm{min}$; Lipophilic Sephadex LH-20; Sigma Co.) eluting with $80 \%$ ethanol. The total polyphenol content was analysed using the Folin-Ciocalteu protocol ${ }^{(16)}$. We used the in vitro yeast transactivation assay ${ }^{(17)}$ and E-screen assay ${ }^{(18)}$ for the screening of oestrogenicity. For the yeast transactivation assay, Saccharomyces cerevisiae ER + LYS 8127 was obtained from Dr K. S. Kang (Seoul National University, Republic of Korea) and stored in $20 \%$ glycerol at $-70^{\circ} \mathrm{C}$. For the E-screen assay, MCF-7 cells were obtained from the Korean Cell Line Bank (Seoul, Republic of Korea) and grown in Roswell Park Memorial Institute (RPMI) 1640 supplemented with $10 \%$ fetal bovine serum, penicillin $(100 \mathrm{U} / \mathrm{ml})$ and insulin $(10 \mu \mathrm{g} / \mathrm{ml})$. Identification of the active component was performed by HPLC (PU-2089; Jasco, Tokyo, Japan) and LC/MS (Hewlett Packard Co., Palo Alto, CA, USA). The ER binding assay measures the capacity of competitor chemical to displace a high binding affinity fluorescent ligand. To determine the relative binding affinity (RBA) of the main active component for ER $\alpha$ and $\mathrm{ER} \beta$, we used an $\mathrm{ER} \alpha$ competitor screening kit (Wako code no. 295-56301; Wako Pure Chemical Industries Ltd, Osaka, Japan) and an ER $\beta$ competitor assay kit (part no. 2700; Invitrogen, Carlsbad, CA, USA). RBA were calculated by dividing the half maximal inhibitory concentration $\left(\mathrm{IC}_{50}\right)$ of unlabelled $\mathrm{E} 2$ by the $\mathrm{IC}_{50}$ of a competitor and then multiplying the value by 100 .

\section{Animal study: animals and diets}

Seventy female Sprague-Dawley rats, aged 5 weeks, were purchased from Orient Bio Inc. (Seongnam, Republic of Korea). The animals were housed under controlled temperature $\left(20 \pm 1^{\circ} \mathrm{C}\right)$, relative humidity $(50-80 \%)$ and illumination
(12 h light-dark) conditions and acclimatised for 1 week. The animals were either ovariectomised (six groups, ten rats in each group) or sham-operated (sham; one group of ten rats). After a 1-week recovery period, the animals were fed the following experimental diet based on AIN-93M (Dyets Inc., Bethlehem, PA, USA) for 6 weeks: two ovariectomised (OVX) groups were supplied with a PCE-containing diet (PCE at a low dose of $0.25 \%$ (PL) or at a high dose of $0.5 \%$ $(\mathrm{PH})$ ); three OVX groups were fed the control diet and injected subcutaneously with bakuchiol (bakuchiol at a low dose of $15 \mathrm{mg} / \mathrm{kg}$ per $\mathrm{d}(\mathrm{BL})$ or at a high dose of $30 \mathrm{mg} / \mathrm{kg}$ per $\mathrm{d}$ (BH)) or E2 (20 $\mu \mathrm{g}$ E2/kg per d; OE group), respectively. The sham and OVX groups were fed the control diet and were treated with the vehicle. Body weight and feed intake of all experimental animals were measured every week. The feed efficiency ratio was calculated as the weight gain $(\mathrm{g})$ divided by feed intake $(\mathrm{g})$.

\section{Serum and tissue collection}

Experimental animals were fasted for $24 \mathrm{~h}$ before dissection. At necropsy, the uterus, livers, kidneys, blood and femurs were collected. Blood was centrifuged for $10 \mathrm{~min}$ at 3000 rpm to separate the serum. The uterus was weighed after the fat was trimmed and again after the connective tissue was trimmed, drained of intra-uterine fluid, and dried at $50^{\circ} \mathrm{C}$ overnight. The livers and kidneys were also trimmed, weighed, and immediately stored at $-70^{\circ} \mathrm{C}$. Femurs were trimmed and stored at $-70^{\circ} \mathrm{C}$.

\section{Analysis of alkaline phosphatase, inorganic-phosphorus, calcium and $17 \beta$-oestradiol concentrations in serum}

Alkaline phosphatase (ALP), inorganic-phosphorus (IP) and $\mathrm{Ca}$ concentrations were measured using commercial reagent kits (Bayer Inc., West Haven, CT, USA) and read in an ADVIA 1650 Auto-analyser (Bayer Inc., Tokyo, Japan). Serum E2 concentration was measured using an E2 Enzyme Immunoassay test kit (BC-1111; BioCheck, Inc., Foster City, CA, USA) and read at $450 \mathrm{~nm}$ in a UV spectrophotometer (V-530; Jasco, Tokyo, Japan). The E2 concentration of the specimens and controls run concurrently with the standards were calculated from the standard curve.

\section{Analysis of femoral bone mineral density}

The bone mineral density (BMD) of the trimmed femurs was analysed using peripheral dual-energy X-ray absorptiometry (models pDEXA Forearm X-Ray Bone Densitometer and pDEXA Sabre; Cooper Surgical Co., Fort Atkinson, WI, USA). BMD values were calculated using the same cross-section of proximal femurs.

\section{Statistical analysis}

All data are presented as mean values with their standard errors. Statistical analysis was performed using ANOVA followed by Duncan's multiple-range test $(P=0.05)$ using a SAS program (SAS Institute Inc., Cary, NC, USA). The $\mathrm{IC}_{50}$ values of the compound binding affinity to $\mathrm{ER} \alpha$ and 
ER $\beta$ were calculated with Sigmaplot 9.0 software (Systat Software Inc., Richmond, CA, USA).

\section{Results}

Identification of oestrogenic component from ethanol extract of Psoralea corylifolia $L$

PCE was fractionated using Sephadex LH-20, and the total phenolic content of each fraction was measured (Appendix 1) and the oestrogenic activities of the main fractions were measured by an in vitro yeast transactivation assay and an E-screen assay. In the yeast transactivation assay, only the no. 40 fraction $(1 \mu \mathrm{g} / \mathrm{ml})$ resulted in $58 \% \beta$-galactosidase activity compared with $10^{-9} \mathrm{M}-\mathrm{E} 2$, whose concentration was shown as having the highest oestrogenicity. The other fractions did not exhibit any oestrogenic activity (Appendix 2 (A)). In the E-screen assay, the no. 40 fraction also showed oestrogenic activity in the range of $0.1-1 \mu \mathrm{g} / \mathrm{ml}$. MCF-7 cells treated with the no. 40 fraction $(0.1 \mu \mathrm{g} / \mathrm{ml})$ showed proliferation at approximately two times higher than that induced by the control (Appendix 2 (B)). The no. 44 and no. 50 fractions showed no significant difference at $0.1 \mu \mathrm{g} / \mathrm{ml}$ compared with the control, while they increased cell growth by 120 and $150 \%$ at $1.0 \mu \mathrm{g} / \mathrm{ml}$, respectively. Taken together, these results indicate that the no. 40 fraction induced the highest effect on MCF-7 proliferation.

To identify the active component from the no. 40 fraction, we performed HPLC and LC/MS analyses. We separated only one peak by HPLC (Appendix 3 (A)), and its major fragmentation ion was $\mathrm{m} / \mathrm{z} 257.3$ in LC/MS (Appendix 3 (B)), which matched the analysis pattern of standard bakuchiol $(\mathrm{m} / \mathrm{z}, 256 \cdot 4)$. Subsequently we identified the active component of no. 40 as bakuchiol.

To determine ER selectivity, the binding affinities of bakuchiol for $\mathrm{ER} \alpha$ and $\mathrm{ER} \beta$ were measured by an in vitro $\mathrm{ER}$ binding assay. The $\mathrm{IC}_{50}$ value for $\mathrm{ER} \alpha$ was $1.34 \times 10^{-6} \mathrm{M}$, while the $\mathrm{IC}_{50}$ value for ER $\beta$ was $1.20 \times 10^{-6} \mathrm{M}$. These values were converted to RBA compared with positive controls (E2). The affinity of bakuchiol for $\mathrm{ER} \alpha$ was three times higher than for $\mathrm{ER} \beta\left(\mathrm{RBA}_{\mathrm{ER} \alpha}=1.51\right.$ and $\left.\mathrm{RBA}_{\mathrm{ER} \beta}=0.44\right)$, indicating that bakuchiol has higher selectivity for $\mathrm{ER} \alpha$.
Effects of ethanol extract of Psoralea corylifolia $L$. and bakuchiol treatments in ovariectomised rats

Body and uterus weight. After 6 weeks, the final body weight of the OVX group was $21.6 \%$ higher than that of the sham group $(P<0.01)$. The body weight was lower in the OE $(78.4 \%)$, PL $(81.4 \%)$ and PH $(74.0 \%)$ groups than in the OVX group. The amount of weight gained by the PL and $\mathrm{PH}$ groups differed significantly from the OVX group; however, the weight gain by the BL and $\mathrm{BH}$ groups did not differ from the OVX group (Table 1). The feed efficiency ratios were about $20 \%$ lower in the OE, PL and PH groups than in the OVX group $(P<0.001)$ despite no significant differences in feed intake. This indicates that PCE supplementation prevented body-weight gain in ovariectomised rats. The weight gain of the uterus was measured to evaluate the uterotrophic activity of bakuchiol and PCE treatments for 6 weeks. The absolute and relative wet uterine weights (weight per $100 \mathrm{~g}$ body weight) decreased by 87 and $90 \%$, respectively, after the ovariectomy operation (Table 2). The uterine weight was 4.7 times higher in the OE group than in the OVX group, although this difference was not significant for either bakuchiol or PCE treatment $(P>0.05)$. Relative liver and absolute kidney weights showed slight changes after PCE treatments (Table 2).

Alkaline phosphatase, calcium, inorganic-phosphorus and $17 \beta$-oestradiol concentrations in serum. ALP, Ca and IP are key factors for bone calcification. ALP and IP concentrations increased by 13 and $23 \%$ in the OVX group compared with the sham group. However, the ALP and IP values in PCE-treated animals were 17 and $10 \%$ lower in the OVX group $(P<0.01)$ and were 24 and $5 \%$ lower in bakuchioltreated animals in the OVX group $(P<0.01$; Table 3$)$. Ca concentration was $3 \%$ lower in the OVX group than in the sham group. PCE and bakuchiol treatment increased Ca levels above $2 \%$ compared with the OVX group $(P<0 \cdot 01)$. These data suggest that both PCE supplements and bakuchiol administration suppressed ALP increases in bone turnover of postovariectomised rats.

The E2 concentration in serum was reduced by the ovariectomy. The E2 concentration was $16 \cdot 9 \mathrm{pg} / \mathrm{ml}$ in

Table 1. Body-weight gain and feed efficiency ratio of ovariectomised rats fed the experimental diets for 4 weeks (Mean values with their standard errors)

\begin{tabular}{|c|c|c|c|c|c|c|}
\hline \multirow[b]{2}{*}{ Group } & \multicolumn{2}{|c|}{$\begin{array}{l}\text { Final body } \\
\text { weight }(g)^{\star *}\end{array}$} & \multicolumn{2}{|c|}{$\begin{array}{l}\text { Body-weight } \\
\text { gain }(g)^{\star \star \star}\end{array}$} & \multicolumn{2}{|c|}{$\begin{array}{l}\text { Feed efficiency } \\
\text { ratio† }(\mathrm{g} / \mathrm{g})^{\star \star \star}\end{array}$} \\
\hline & Mean & SE & Mean & SE & Mean & SE \\
\hline Sham-operated group & $259^{b}$ & 35.57 & $180^{\mathrm{b}}$ & 34.88 & $0.22^{c}$ & 0.03 \\
\hline OVX & $315^{\mathrm{a}}$ & 28.35 & $236^{\mathrm{a}}$ & $28 \cdot 76$ & $0.27^{a}$ & 0.03 \\
\hline $\mathrm{OE}$ & $259^{b}$ & 21.81 & $181^{\mathrm{b}}$ & 21.99 & $0.22^{c}$ & 0.02 \\
\hline $\mathrm{BL}$ & $299^{a}$ & $22 \cdot 22$ & $220^{\mathrm{a}}$ & 23.33 & $0.24^{b, c}$ & 0.02 \\
\hline $\mathrm{BH}$ & $311^{a}$ & $15 \cdot 83$ & $233^{a}$ & $15 \cdot 34$ & $0.25^{\mathrm{b}}$ & 0.01 \\
\hline PL & $267^{\mathrm{b}}$ & 13.51 & $189^{b}$ & $15 \cdot 37$ & $0.23^{\mathrm{c}}$ & 0.03 \\
\hline $\mathrm{PH}$ & $246^{\mathrm{b}}$ & $16 \cdot 65$ & $168^{\mathrm{b}}$ & $15 \cdot 34$ & $0.22^{c}$ & 0.02 \\
\hline
\end{tabular}

OVX, ovariectomised vehicle-treated control group; OE, $17 \beta$-oestradiol-administered group ( $+20 \mu \mathrm{g} 17 \beta$-oestradiol $/ \mathrm{kg} \mathrm{per} \mathrm{d);} \mathrm{BL,} \mathrm{bakuchiol-}$ administered group with low dose $(+15 \mathrm{mg} / \mathrm{kg}$ per d); $\mathrm{BH}$, bakuchiol-administered group with high dose $(+30 \mathrm{mg} / \mathrm{kg}$ per d); $\mathrm{PL}$, ethanol extract of Psoralea corylifolia L. (PCE)-supplemented group with low dose (+0.25\% PCE); PH, PCE-supplemented group with high dose (+0.5\% PCE). a,b,c Mean values within a column with unlike superscript letters were significantly different $(P<0.05$; Duncan's multiple-range test).

${ }^{\star} P<0.05,{ }^{* \star} P<0.01,{ }^{* \star} P<0.001$ (ANOVA)

† Weight gain (g)/feed intake (g). 
Table 2. Effect of ethanol extract of Psoralea corylifolia L. (PCE) and bakuchiol treatments on the organ weight of ovariectomised rats fed the diets experimental for 4 weeks

(Mean values with their standard errors)

\begin{tabular}{|c|c|c|c|c|c|c|c|c|c|c|c|c|}
\hline \multirow[b]{3}{*}{ Group } & \multicolumn{4}{|c|}{ Uterus } & \multicolumn{4}{|c|}{ Liver } & \multicolumn{4}{|c|}{ Kidney } \\
\hline & \multicolumn{2}{|c|}{ Absolute $(\mathrm{mg})^{\star \star \star}$} & \multicolumn{2}{|c|}{$\begin{array}{c}\text { Relative } \\
(\mathrm{mg} / 100 \mathrm{~g})^{\star \star \star}\end{array}$} & \multicolumn{2}{|c|}{ Absolute (g) } & \multicolumn{2}{|c|}{$\begin{array}{l}\text { Relative } \\
(\mathrm{g} / 100 \mathrm{~g})^{\star}\end{array}$} & \multicolumn{2}{|c|}{ Absolute $(\mathrm{g})^{\star \star \star}$} & \multicolumn{2}{|c|}{$\begin{array}{l}\text { Relative } \\
(\mathrm{g} / 100 \mathrm{~g})\end{array}$} \\
\hline & Mean & SE & Mean & SE & Mean & SE & Mean & SE & Mean & SE & Mean & SE \\
\hline Sham-operated group & $522 \cdot 2^{\mathrm{a}}$ & $70 \cdot 00$ & $206 \cdot 8^{\mathrm{a}}$ & 54.42 & $6 \cdot 80^{\mathrm{b}}$ & 0.40 & $2 \cdot 72^{\mathrm{a}, \mathrm{b}}$ & 0.08 & $1.77^{\mathrm{a}}$ & 0.11 & $0.60^{a, b}$ & 0.23 \\
\hline OVX & $69.5^{\mathrm{c}}$ & $6 \cdot 37$ & $22 \cdot 2^{\mathrm{c}}$ & $2 \cdot 71$ & $7 \cdot 74^{a}$ & 0.47 & $2 \cdot 47^{b}$ & 0.21 & $1 \cdot 82^{\mathrm{a}}$ & 0.16 & $0.58^{\mathrm{b}}$ & 0.07 \\
\hline $\mathrm{OE}$ & $332 \cdot 8^{\mathrm{b}}$ & 22.54 & $128 \cdot 1^{\mathrm{b}}$ & 6.05 & $7.56^{a, b}$ & 0.52 & $2 \cdot 98^{a}$ & 0.13 & $1 \cdot 81^{\mathrm{a}}$ & 0.23 & $0.69^{a}$ & 0.03 \\
\hline $\mathrm{BL}$ & $75 \cdot 9^{c}$ & 7.61 & $25 \cdot 1^{\mathrm{c}}$ & $3 \cdot 17$ & $7 \cdot 55^{\mathrm{a}, \mathrm{b}}$ & 0.67 & $2 \cdot 61^{\mathrm{b}}$ & 0.17 & $1 \cdot 82^{\mathrm{a}, \mathrm{b}}$ & 0.17 & $0 \cdot 61^{\mathrm{a}, \mathrm{b}}$ & 0.05 \\
\hline $\mathrm{BH}$ & $82 \cdot 7^{c}$ & $6 \cdot 14$ & $26 \cdot 5^{\mathrm{c}}$ & $2 \cdot 23$ & $7 \cdot 73^{\mathrm{a}}$ & 0.33 & $2 \cdot 49^{b}$ & 0.09 & $1.85^{a}$ & 0.11 & $0.59^{\mathrm{b}}$ & 0.03 \\
\hline PL & $78.9^{c}$ & $6 \cdot 86$ & $28.8^{\mathrm{C}}$ & $2 \cdot 13$ & $7 \cdot 84^{a}$ & 0.87 & $2.93^{\mathrm{a}}$ & 0.30 & $1 \cdot 72^{\mathrm{a}, \mathrm{b}}$ & 0.17 & $0.64^{\mathrm{a}, \mathrm{b}}$ & 0.05 \\
\hline $\mathrm{PH}$ & $94 \cdot 4^{\mathrm{C}}$ & $6 \cdot 14$ & $38 \cdot 2^{\mathrm{c}}$ & 2.23 & $7 \cdot 40^{\mathrm{a}, \mathrm{b}}$ & 0.86 & $2.99^{a}$ & 0.28 & $1 \cdot 61^{\mathrm{b}}$ & 0.13 & $0 \cdot 65^{a, b}$ & 0.04 \\
\hline
\end{tabular}

OVX, ovariectomised vehicle-treated control group; OE, 17ß-oestradiol-administered group ( $+20 \mu \mathrm{g} 17 \beta$-oestradiol/kg per d); BL, bakuchiol-administered group with low dose $(+15 \mathrm{mg} / \mathrm{kg}$ per d); $\mathrm{BH}$, bakuchiol-administered group with high dose $(+30 \mathrm{mg} / \mathrm{kg}$ per d); PL, PCE-supplemented group with low dose (+0.25\% PCE); PH, PCEsupplemented group with high dose $(+0.5 \%$ PCE).

a,b,c Mean values within a column with unlike superscript letters were significantly different $(P<0.05$; Duncan's multiple-range test).

${ }^{\star} P<0.05,{ }^{* \star \star} P<0.001$ (ANOVA).

the sham group and $4 \mathrm{pg} / \mathrm{ml}$ in the OVX group (Fig. 1 (A)). The E2 concentration was $6 \cdot 25$ times higher in the OE group than in the OVX group. Compared with the OVX group, the E2 concentrations were 3.25 times higher in the $\mathrm{BL}$ group, 5.25 times higher in the $\mathrm{BH}$ group, 2.75 higher times in the PL group and 4.5 times higher in the $\mathrm{PH}$ group. These data suggest that bakuchiol was more effective than PCE in increasing the E2 concentration in blood after ovariectomy.

The BMD of the proximal femur was $112.3($ SE 0.9$) \mathrm{mg} / \mathrm{cm}^{2}$ in the $\mathrm{PH}$ group and 114.8 (SE 1.1) $\mathrm{g}$ in the $\mathrm{BH}$ group, and these values were significantly higher than in the OVX group $\left(102.8(\mathrm{SE} 1.5) \mathrm{mg} / \mathrm{cm}^{2} ; P<0.001\right)$. BMD in the PL group $\left(103.8(\mathrm{SE} 2.3) \mathrm{mg} / \mathrm{cm}^{2}\right)$ and in the BL group (106.4 (SE 2.0$) \mathrm{mg} / \mathrm{cm}^{2}$ ) did not differ significantly from that of the OVX group. The BMD was similar in the $\mathrm{BH}$ and $\mathrm{OE}$ groups, and $11 \%$ higher than in the OVX group. The BMD in the $\mathrm{PH}$ group was $9 \%$ higher than in the OVX group (Fig. 1 (B)).

\section{Discussion}

Based on the results of observational and epidemiological studies, phyto-oestrogens have been shown to help alleviate symptoms of menopause and to reduce the risk of CVD and oestrogen-dependent cancers. Despite evidence supporting the health benefits of phyto-oestrogens ${ }^{(19)}$, genistein and soya protein stimulate tumour growth in a dose-dependent manner in ovariectomised athymic mice implanted with MCF-7 cells ${ }^{(20)}$. Many new potent phyto-oestrogens from medicinal plants such as red clover, dong quai, soya and fo-ti have been investigated for development into new drugs that will hopefully provide alternatives to $\mathrm{HRT}^{(21-24)}$. $P$. corylifolia $\mathrm{L}$. is also a source of phyto-oestrogens because PCE contains oestrogen-like compounds such as coumarin and members of the flavonoid family.

The yeast transactivation assay and E-screen assay are routinely used for phyto-oestrogen screening, and the ER binding assay is performed to compare binding affinity for the $\mathrm{ER}^{(25)}$.

Table 3. Effect of ethanol extract of Psoralea corylifolia L. (PCE) and bakuchiol treatments on serum alkaline phosphatase (ALP), calcium and inorganic phosphorus (IP) concentrations of ovariectomised rats fed the experimental diets for 4 weeks

(Mean values with their standard errors)

\begin{tabular}{|c|c|c|c|c|c|c|}
\hline \multirow[b]{2}{*}{ Group } & \multicolumn{2}{|c|}{$\operatorname{ALP}(U / /)^{\star \star \star}$} & \multicolumn{2}{|c|}{$\mathrm{Ca}\left(\mathrm{mg} / \mathrm{l}^{\star \star \star \star}\right.$} & \multicolumn{2}{|c|}{ IP $(\mathrm{mg} / \mathrm{l})^{\star \star \star}$} \\
\hline & Mean & SE & Mean & SE & Mean & $\mathrm{SE}$ \\
\hline Sham-operated group & $109 \cdot 0^{\mathrm{a}, \mathrm{b}}$ & 13.39 & $110 \cdot 4^{b}$ & 3.5 & $66 \cdot 9^{c}$ & $7 \cdot 7$ \\
\hline OVX & $123 \cdot 8^{a}$ & $10 \cdot 64$ & $107.4^{c}$ & 3.0 & $82.4^{a}$ & 7.5 \\
\hline $\mathrm{OE}$ & $81 \cdot 5^{\mathrm{c}}$ & 11.77 & $117.4^{\mathrm{a}}$ & 3.1 & $65 \cdot 1^{\mathrm{c}}$ & $7 \cdot 7$ \\
\hline $\mathrm{BL}$ & $94 \cdot 6^{\mathrm{b}, \mathrm{c}}$ & 9.18 & $110.9^{b}$ & 3.5 & $80.9^{b}$ & $5 \cdot 2$ \\
\hline $\mathrm{BH}$ & $94 \cdot 6^{\mathrm{b}, \mathrm{c}}$ & 16.93 & $112 \cdot 7^{\mathrm{b}}$ & 3.0 & $76 \cdot 0^{\mathrm{b}}$ & $6 \cdot 0$ \\
\hline PL & $106 \cdot 0^{\mathrm{a}, \mathrm{b}}$ & 12.66 & $109 \cdot 9^{\mathrm{b}, \mathrm{c}}$ & $2 \cdot 7$ & $75 \cdot 9^{\mathrm{b}}$ & 9.2 \\
\hline $\mathrm{PH}$ & $99 \cdot 2^{\mathrm{b}, \mathrm{c}}$ & 12.66 & $110 \cdot 3^{\mathrm{b}}$ & $2 \cdot 6$ & $73.0^{\mathrm{b}}$ & 4.4 \\
\hline
\end{tabular}

OVX, ovariectomised vehicle-treated control group; OE, 17 $\beta$-oestradiol-administered group $(+20 \mu \mathrm{g} 17 \beta$-oestradiol/kg per d); BL, bakuchiol-administered group with low dose $(+15 \mathrm{mg} / \mathrm{kg}$ per d); $\mathrm{BH}$, bakuchiol-administered group with high dose $(+30 \mathrm{mg} / \mathrm{kg}$ per d); PL, PCE-supplemented group with low dose $(+0.25 \% \mathrm{PCE})$; $\mathrm{PH}$ PCE-supplemented group with high dose (+0.5\% PCE).

a,b,c Mean values within a column with unlike superscript letters were significantly different $(P<0.05$; Duncan's multiple-range test).

${ }^{\star \star \star} P<0.001$ (ANOVA). 


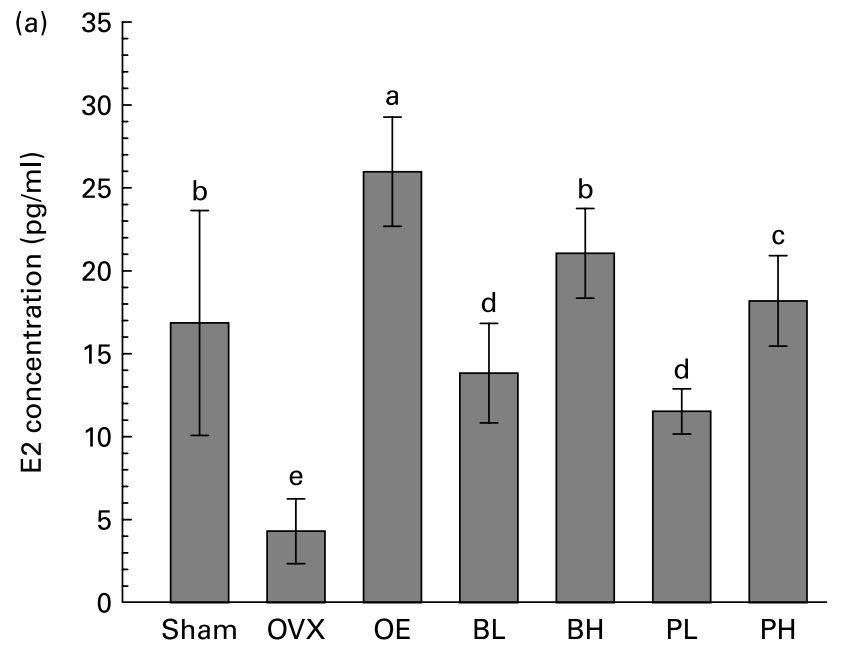

(b) 120

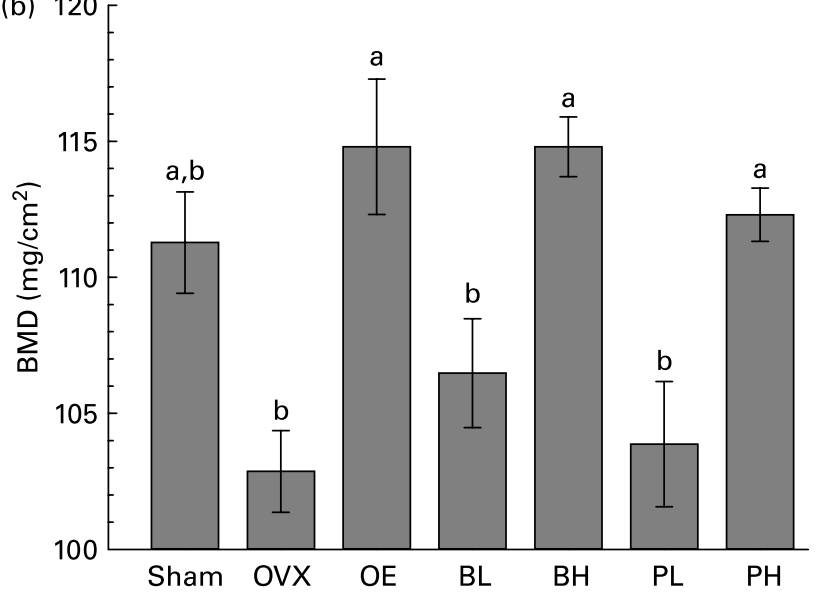

Fig. 1. Effect of ethanol extract of Psoralea corylifolia L. (PCE) and bakuchiol treatments on $17 \beta$-oestradiol $(E 2)$ serum concentration $(A)$ and bone mineral density (BMD) of the proximal femur (B) in ovariectomised rats. OVX, ovariectomised vehicle-treated control group; OE, E2-administered group $(+20 \mu \mathrm{g}$ E2/kg per d); BL, bakuchiol-administered group with low dose $(+15 \mathrm{mg} / \mathrm{kg}$ per d); $\mathrm{BH}$, bakuchiol-administered group with high dose $(+30 \mathrm{mg} / \mathrm{kg}$ per d); PL, PCE-supplemented group with low dose (+0.25\% PCE); PH, PCE-supplemented group with high dose $(+0.5 \%$ PCE). Values are means, with standard errors represented by vertical bars. ${ }^{a-e}$ Mean values with unlike letters were significantly different $(P<0.05$; Duncan's multiple-range test). For E2 and BMD, $P<0.001$ (ANOVA).

In the present study, only one of ninety fractions by gel chromatography was identified by the in vitro assays as the most oestrogenic fraction. The active component from that fraction was identified as bakuchiol by HPLC and LC/MS. Wang et al. proposed that corylin and bavachin can stimulate bone formation and may have potential activity against osteoporosis in osteoblast-like UMR106 cells ${ }^{(15)}$. However, the present results show that only the bakuchiol-containing fraction had oestrogenic activity in the in vitro assays. In the ER binding assay, the affinity of bakuchiol for ER $\alpha$ was three times higher than for $\mathrm{ER} \beta$. ER $\alpha$ has been shown to cause breast cancer cell proliferation, and ER $\beta$ has been demonstrated to be a tumour suppressor $^{(26,27)}$. However, Hertrampf et al. ${ }^{(28)}$ suggested that only $\mathrm{ER} \alpha$ agonists confer bone-protective effects. The present results showing a higher selectivity of bakuchiol for $\mathrm{ER} \alpha$ may result in a protective effect for bone loss.
We evaluated the effects of PCE and bakuchiol treatment on body-weight gain, uterine weight and bone loss in ovariectomised rats. Body-weight gain is associated with metabolic abnormalities in postmenopausal women, and oestrogen treatment decreases weight gain and visceral fat development in animals and humans ${ }^{(26,27)}$. The PCE-supplemented groups gained significantly less weight than the OVX group and a similar amount of weight as the sham and OE groups, whereas weight gain was similar in the bakuchiol-treated groups and the OVX group. Szkudelska, Nogowski reported that genistein decreased body- and fat tissue-weight gain, and that these changes are accompanied by lower feed intake ${ }^{(29)}$. However, in our experiments, the feed intake did not differ significantly between the bakuchiol- and PCE-treated groups and the OVX and $\mathrm{OE}$ groups. The feed efficiency ratio was similar in all groups except the OVX and $\mathrm{BH}$ groups.

The uterotrophic effects of oestrogen treatment are undesirable in postmenopausal women because they may increase the risk of endometrial cancer ${ }^{(9)}$. The goal of many studies is to identify a new phyto-oestrogen as an alternative to HRT for preventing osteoporosis without causing uterine hormone stimulation. However, there is an ongoing controversy about phytooestrogens and their uterotrophic effects. Anderson et al. ${ }^{(30)}$ provided evidence that genistein treatment $(0.5,1.6$ and $5.0 \mathrm{mg} / \mathrm{d})$ did not exhibit any uterotrophic activity, but showed dosage-dependent biphasic effects on bone tissue in the ovariectomised rat model. However, Fanti et al. ${ }^{(31)}$ reported that higher genistein doses $(50 \mu \mathrm{g} / \mathrm{g}$ body weight) caused an increase in uterine mass. Other studies with genistein and daidzein have also demonstrated weak oestrogenic effects, as reflected by changes in uterine weight ${ }^{(29,32,33)}$. The effect of dietary equol on uterotrophic activity is 3.5 times less than the effect of E2 treatment, and equol shows weak uterotrophic activity in mice ${ }^{(7)}$. In the present study, uterine weight was much lower in the OVX group with oestrogen deficiency than in the sham and E2-treated groups. Bakuchiol administration and PCE supplementation had no effect on uterine weight increase. These results suggest that bakuchiol and PCE treatment have no uterotrophic activity, despite having significant oestrogenic activity. Taken together, these data suggest that bakuchiol and PCE treatments may alleviate menopausal symptoms without increasing the risk of cancer in postmenopausal women.

Decreased plasma E2 and increased bone loss are the most prevalent symptoms in postmenopausal women. It has been well documented that isoflavone or other phyto-oestrogen supplements modulate plasma E2 and exert a protective effect on bone loss ${ }^{(34)}$. However, genistein has been shown to have adverse effects on tumours and on the uterus in women with postmenopausal breast cancer, despite beneficial effects on bone ${ }^{(35)}$. Genistein also shows both positive and negative effects on experimental endothelial dysfunction ${ }^{(36)}$. In addition, pomegranate extract inhibits ovariectomy-stimulated bone turnover ${ }^{(37)}$, and high dietary levels of soya isoflavones do not stimulate breast or uterine proliferation in postmenopausal monkeys and may contribute to an oestrogen profile associated with reduced breast cancer risk ${ }^{(38)}$. Our present data suggest that bakuchiol and PCE supplementation significantly increase the plasma E2 level, suggesting that bakuchiol acts as a potent phyto-oestrogen.

We found that both bakuchiol and PCE treatments in ovariectomised rats resulted in lower ALP and IP in serum, higher 
$\mathrm{Ca}$ in serum, and increased BMD of the proximal femur. ALP is a key enzyme for bone calcification and provides an index of cell differentiation for bone formation ${ }^{(39)}$. Increased ALP levels indicate a positive effect on osteoblastic differentiation, particularly bone mineralisation $^{(40)}$. The ALP concentration was significantly higher in the OVX group than in other groups, suggesting that ovariectomy increases bone turnover rate ${ }^{(41)}$. E2 administration significantly suppressed the increase of serum ALP levels. Rats treated with bakuchiol or PCE had lower ALP levels than those in the OVX and sham groups. Bakuchiol administration was most effective and had only a slightly different effect than E2 treatment. Usually, osteoclasis is induced when the Ca:IP ratio decreases $^{(42)}$. In the present study, bakuchiol and PCE treatments may have attenuated bone loss by decreasing the IP levels and by slightly increasing $\mathrm{Ca}$ concentration in serum. An increase in BMD was also observed in the proximal femur of ovariectomised rats. Surprisingly, the $\mathrm{BH}$ and $\mathrm{PH}$ groups exhibited significantly higher BMD than the sham group, and similar BMD to the E2treated group. The serum E2 concentration was also consistent with the BMD results. Zhang et al. reported that PCE inhibits bone resorption in vitro ${ }^{(14)}$ and that an acetone extract of $P$. corylifolia L. significantly increases serum IP and promotes bone calcification in rats ${ }^{(10)}$. The present results suggest that bakuchiol and PCE supplementation can reduce postmenopausal bone loss without the need for oestrogen.

In the present study, we screened oestrogenic compounds from PCE by in vitro assays and identified bakuchiol as the most active component. Bakuchiol showed a higher selectivity for $\mathrm{ER} \alpha$ than for ER $\beta$, which could be related to its bone-protective properties. In our animal study, bakuchiol or PCE treatments were effective in preventing bone loss without significant uterotrophic activity in ovariectomised rats. In conclusion, bakuchiol and PCE treatments should be effective in preventing bone loss and could be potent phyto-oestrogens and useful alternatives to HRT.

\section{Acknowledgements}

The present study was supported by a grant of the Korea Science and Engineering Foundation (KOSEF) funded by the Ministry of Science and Technology and by a grant from the Korea Food Research Institute, Republic of Korea. The authors thank Y. S. Kim, Korea Research Institute of Chemical Technology, Republic of Korea for providing pure standard compounds and Professor K. S. Kang, College of Veterinary Medicine, Seoul National University, Republic of Korea for providing Saccharomyces cerevisiae ER + LYS 8127. S.-H. L., H. J. P. and S. K. developed the initial idea, S.-H. L., S.-R. K. and S. K. collected and analysed the data from in vitro assays and instrumental analyses, T.-Y. H. and J. A. performed the animal study, and S. K. drafted the manuscript. The authors declare no conflict of interest.

\section{References}

1. Pike MC, Pearce CL \& Wu AH (2004) Prevention of cancers of the breast, endometrium and ovary. Oncogene 23, 6379-6391.

2. Carr MC (2003) The emergence of the metabolic syndrome with menopause. J Clin Endocrinol Metab 88, 2404-2411.
3. Quereda F, Mendoza N, Olalla MA, Baro F \& Duran M (2005) Prophylactic approach for asymptomatic post-menopausal women: osteroporosis. Maturitas 15, S38-S45.

4. Ito K (2007) Hormone replacement therapy and cancers: the biological roles of estrogen and progestin in tumorigenesis are different between the endometrium and breast. Tohoku $J$ Exp Med 212, 1-12.

5. Yadava RN \& Verma YA (2005) A new biologically active flavonol glycoside from Psoralea corylifolia (Linn.). J Asian Nat Prod Res 7, 671-675.

6. Fujioka M, Uehara M, Wu J, Adlercreutz H, Suzuki K, Kanazawa K, Takeda K, Yamada K \& Ishimi Y (2004) Equol, a metabolite of daidzein, inhibits bone loss in ovariectomized mice. J Nutr 134, 2623-2627.

7. Rachon D, Vortherms T, Seidlova-Wuttke D \& Wuttke W (2007) Effects of dietary equol on body weight gain, intra-abdominal fat accumulation, plasma lipids, and glucose tolerance in ovariectomized Sprague-Dawley rats. Menopause 22, 1-8.

8. Mathey J, Mardon J, Fokialakis N, et al. (2007) Modulation of soy isoflavones bioavailability and subsequent effects on bone health in ovariectomized rats: the case for equol. Osteoporos Int 18, 671-679.

9. Weiderpass E, Adami HO, Baron JA, Magnusson C, Bergstrom R, Lindgren A, Correia N \& Persson I (1999) Risk of endometrial cancer following estrogen replacement with and without progestins. J Natl Cancer Inst 91, 1131-1137.

10. Miura H, Nishida H \& Iinuma M (1996) Effect of crude fractions of Psoralea corylifolia seed extract on bone calcification. Planta Med 62, 150-153.

11. Haraguchi H, Inoue J, Tamura Y \& Mizutani K (2002) Antioxidative components of Psoralea corylifolia (Leguminosae). Phytother Res 16, 539-544.

12. Karsura H, Tsukiyama RI, Suzuki A \& Kobayashi M (2001) In vitro antimicrobial activities of bakuchiol against oral microorganisms. Antimicrob Agents Chemother 45, 3009-3013.

13. Ferrándiz ML, Gil B, Sanz MJ, Ubeda A, Erazo S, González E, Negrete R, Pacheco S, Payá M \& Alcaraz MJ (1996) Effect of bakuchiol on leukocyte functions and some inflammatory responses in mice. J Pharm Pharmacol 48, 975-980.

14. Zhang CZ, Wang SX, Zhang Y, Chen JP \& Liang XM (2005) In vitro estrogenic activities of Chinese medicinal plants traditionally used for the management of menopausal symptoms. J Ethnopharmacol 98, 295-300.

15. Wang D, Li F \& Jiang Z (2001) Osteoblastic proliferation stimulating activity of Psoralea corylifolia extracts and two of its flavonoids. Planta Med 67, 748-749.

16. Singleton VL \& Rossi JA (1965) Colorimetry of total phenolics with phosphomolybdic-phosphotungstic acid reagents. Am J Enol Vitic 16, 144-158.

17. Gaido KW, Leonard LS, Lovell S, Gould JC, Babai D, Portier CJ \& McDonnell DP (1997) Evaluation of chemicals with endocrine modulating activity in a yeast-based steroid hormone receptor gene transcription assay. Toxidol Apply Pharmacol 143, 205-212.

18. Soto A, Sonnenschein C, Chung KL, Fernandez MF, Olea N \& Serrano FO (1995) The E-SCREEN assay as a tool to identify estrogens: an update on estrogenic environmental pollutants. Environ Health Pers 103, 113-122.

19. Anderson JJ, Anthony MS, Cline JM, Washburn SA \& Garner SC (1999) Health potential of soy isoflavones for menopausal women. Public Health Nutr 2, 489-504.

20. Messina MJ \& Loprinzi CL (2001) Soy for breast cancer survivors: a critical review of the literature. J Nutr 131, Suppl. 11, 3095S-3108S. 
21. Liu J, Buredette $\mathrm{J}, \mathrm{Xu} \mathrm{H}$, et al. (2001) Evaluation of estrogenic activity of plant extracts for the potential treatment of menopausal symptoms. J Agric Food Chem 49, 2472-2479.

22. Kroneberg F \& Fugh-Berman A (2002) Complementary and alternative medicine for menopausal symptoms: a review of randomized, controlled trials. Ann Intern Med 137, 805-813.

23. Dog TL, Powell KL \& Weisman SM (2003) Critical evaluation of the safety of Cimicifuga racemosa in menopause symptom relief. Menopause 10, 299-313.

24. Mishima S, Suzuki KM, Isohama Y, Kuratsu N, Araki Y, Inoue M \& Miyata T (2005) Royal jelly has estrogenic effects in vitro and in vivo. J Ethnopharmacol 101, 215-220.

25. Coldham NG, Dave M, Sivapathasundaram S, McDonnell DP, Connor C \& Sauer MJ (1997) Evaluation of a recombinant yeast cell estrogen screening assay. Environ Health Perspect 105, 734-742.

26. Paruthiyil S, Parmar H, Kerekatte V, Cunha GR, Firestone GL \& Leitman DC (2004) Estrogen receptor $\beta$ inhibits human breast cancer cell proliferation and tumor formation by causing a G2 cell cycle arrest. Cancer Res 64, 423-428.

27. Strom A, Hartman J, Foster JS, Kietz S, Wimalasena J \& Gustafsson JA (2004) Proc Natl Acad Sci U S A 101, $1566-1571$

28. Hertrampf T, Gruca MJ, Seibel J, Laudenbach U, Fritzemeier KH \& Diel P (2007) The bone-protective effect of the phytoestrogen genistein is mediated via ER $\alpha$-dependent mechanisms and strongly enhanced by physical activity. Bone 40, $1529-1535$.

29. Szkudelska K \& Nogowski L (2007) Genistein-A dietary compound inducing hormonal and metabolic changes. J Steroid Biochem Mol Biol 17, 1-9.

30. Anderson JJB, Ambrose WW \& Garner SC (1998) Biphasic effects of genistein on bone tissue in the ovariectomized lactating rat model. Proc Soc Exp Biol Med 217, 345-350.

31. Fanti P, Monier-Faugere MC, Geng Z, Schmidt J, Morris PE, Cohen D \& Malluche HH (1998) The phytoestrogen genistein reduces bone loss in short-term ovariectomized rats. Osteoporos Int 8, 274-281.

32. Richter CP \& Uhlenhuth EH (1954) Comparison of the effects of gonadectomy of spontaneous activity of wild and domesticated Norway rats. Endocrinology 54, 311-322.
33. Tchernof A, Calles-Escandon J, Sites CK \& Poehlman ET (1998) Menopause, central body fatness, and insulin resistance: effects of hormone-replacement therapy. Coron Artery Dis 9, 503-511.

34. Mehmood Z, Smith AG, Tucker MJ, Chuzel F \& Carmichael NG (2000) The development of methods for assessing the in vivo oestrogen-like effects of xenobiotics in CD-1 mice. Food Chem Toxicol 38, 493-501.

35. Picherit C, Dalle M, Neliat G, Lebecgue P, Davicco MJ, Barlet JP \& Coxam V (2000) Genistein and daidzein modulate in vitro rat uterine contractile activity. J Steroid Biochem Mol Biol 75, 201-208.

36. Santell RC, Chang YC, Nair MG \& Helferich WG (1997) Dietary genistein exerts estrogenic effects upon the uterus, mammary gland and the hypothalamic/pituitary axis in rats. J Nutr 127, 263-269.

37. Alekel DL, Germain AS, Peterson CT, Hanson KB, Stewart JW \& Toda T (2000) Isoflavone-rich soy protein isolate attenuates bone loss in the lumbar spine of perimenopausal women. $\mathrm{Am}$ J Clin Nutr 72, 844-852.

38. Power KA, Ward WE, Chen JM, Saarinen NM \& Thompson LU (2006) Genistein alone and in combination with the mammalian lignans enterolactone and enterodiol induce estrogenic effects on bone and uterus in a postmenopausal breast cancer mouse model. Bone 39, 117-124.

39. Squadrito F, Altavilla D, Squadrito G, et al. (2002) Genistein supplementation and estrogen replacement therapy improve endothelial dysfunction induced by ovariectomy in rats. Cardiovasc Res 45, 454-462.

40. Mori-Okamoto J, Otawara-Hamamoto Y, Yamato H \& Yoshimura M (2004) Pomegranate extract improves a depressive state and bone properties in menopausal syndrome model ovariectomized mice. J Ethnopharmacol 92, 93-101.

41. Wood CE, Register TC, Anthony MS, Kock ND \& Cline JM (2004) Breast and uterine effects of soy isoflavones and conjugated equine estrogens in postmenopausal female monkeys. $J$ Clin Endocrinol Metab 89, 3462-3468.

42. Xiong Z, Wang D, Xu Y \& Li F (2003) Osteoblastic differentiation bioassay and its application to investigating the activity of fractions and compounds from Psoralea corylifolia L. Pharmazie 58, 925-928. 


\section{Appendix}

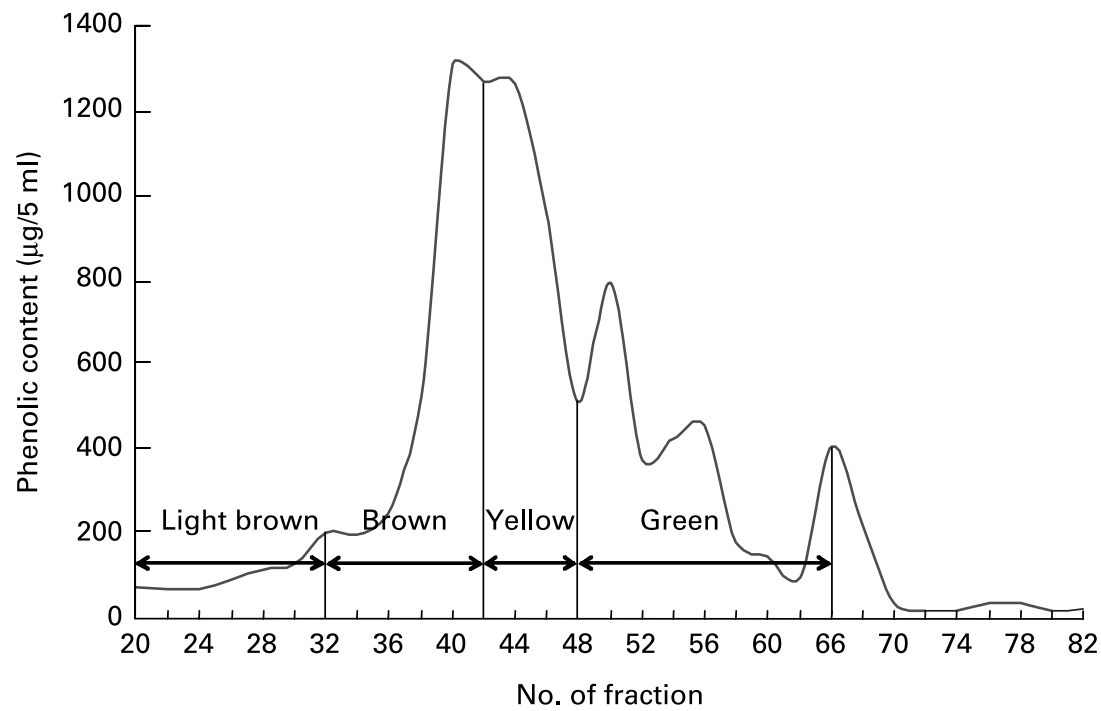

Appendix 1. Total phenolic contents of each fraction separated by Sephadex LH-20 $(1.5 \times 120 \mathrm{~cm}, 1 \mathrm{ml} / \mathrm{min}$; Sigma Co., St Louis, MO, USA) from Psoralea corylifolia L. extract using the Folin-Ciocalteu protocol ${ }^{(16)}$. A total of $100 \mu \mathrm{l}$ of ethanol extract of Psoralea corylifolia L. was mixed with $2 \mathrm{ml}$ of $2 \% \mathrm{Na}_{2} \mathrm{CO}_{3}$ for $2 \mathrm{~min}$ at room temperature and then added to $100 \mu \mathrm{l}$ of $50 \%$ Folin-Ciocalteu reagent. After $30 \mathrm{~min}$, the total polyphenol content was measured at $750 \mathrm{~nm}$ using a UV spectrophotometer (V-530; Jasco, Tokyo, Japan). Catechin was used as the standard.
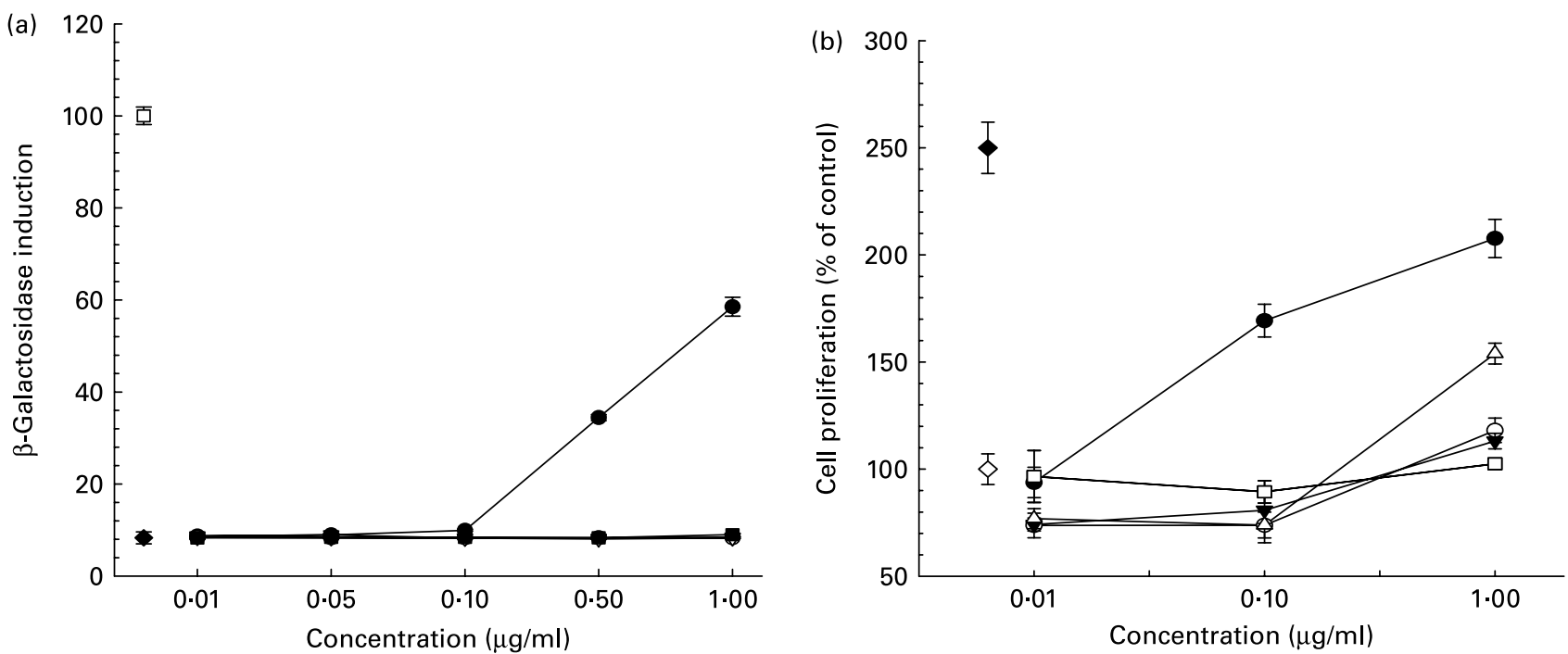

Appendix 2. Oestrogenic activities of the main fractions evaluated by in vitro yeast recombinant assay (a) and E-screen assay (b). Data represent only the five main fractions shown in Appendix 1. The fractions evaluated by the in vitro yeast recombinant assay were: no. $40(\bullet)$; no. $44(0)$; no. 50 ( $\nabla)$; no. $56(\nabla)$; no. 66 $(\square)$; $17 \beta$-oestradiol $\left(10^{-9} \mathrm{M}\right)(\square)$; control $(\bullet)$. The fractions evaluated by the E-screen assay were: no. $40(\bullet)$; no. $44(\mathbf{\nabla}) ;$ no. $50(\Delta)$; no. $56(\square)$; no. $66(\square)$; $17 \beta$-oestradiol $\left(10^{-9} \mathrm{M}\right)(\diamond)$; control $(\diamond)$. 

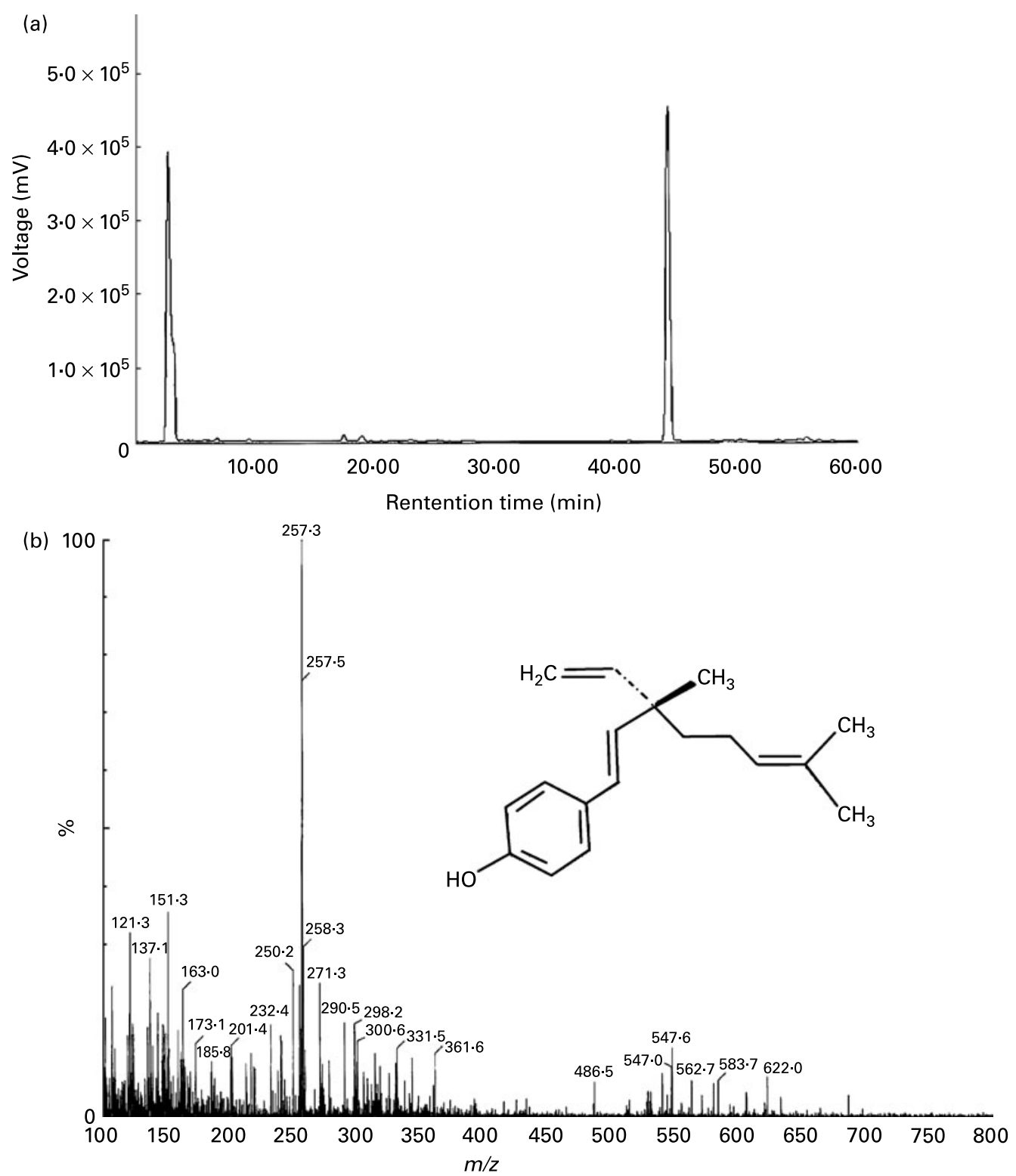

Appendix 3. Identification of bakuchiol (retention time $43.25 \mathrm{~min}$ ) as the oestrogenic component from fraction no. 40 by HPLC (a) and LC/MS (b). (a) Chromatographic separation using an XTerra $\mathrm{RP}_{18}$ column $\left(4.6 \times 250 \mathrm{~mm}, 5 \mu \mathrm{m}\right.$; Waters Co., Milford, MA, USA) at $25^{\circ} \mathrm{C}$ in an HPLC system (PU-2089; Jasco, Tokyo, Japan). The mobile phase comprised $0.1 \%$ water-acetic acid (A) and acetonitrile (B); the A:B ratio was as follows: $0 \mathrm{~min}, 60: 40 ; 15 \mathrm{~min}, 50: 50$; $35 \mathrm{~min}, 40: 60$; $45 \mathrm{~min}, 30: 70 ; 55 \mathrm{~min}, 20: 80$ and maintained for $5 \mathrm{~min}$. The flow rate was $1.0 \mathrm{ml} / \mathrm{min}$; the detector wavelength was $245 \mathrm{~nm}$; the injection volume was $20 \mu \mathrm{l}$. (b) A Quattro LC triple-quadrupole Tandem MS (Hewlett Packard Co., Palo Alto, CA, USA), equipped with an electrospray ionisation source, was used for MS analyses. The ionisation mode was positive, and the interface and mass selective detector parameters were as follows: flow, $0.001-10 \mathrm{ml} / \mathrm{min}$; diode array detector, $190-$ $950 \mathrm{~nm}$; gas flow, 91 litres/h; desolvation gas flow, 473 litres/h; capillary, $3.7 \mathrm{kV}$; cone, $30 \mathrm{~V}$; extractor, $3 \mathrm{~V}$; Rangefinder (RF) lens, $0.51 \mathrm{~V}$; source block temperature, $80^{\circ} \mathrm{C}$; desolvation temperature, $200^{\circ} \mathrm{C}$. 